\title{
Un immense défi pour nous tous
}

\section{Carlos B. Quinto}

Dr méd., membre du Comité central de la FMH, responsable du département Santé publique et professions de la santé

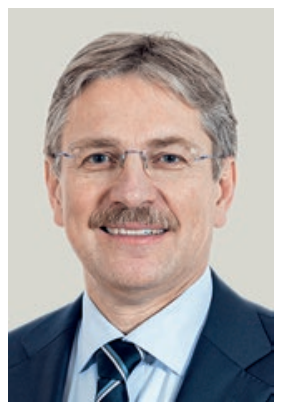

Cela fait maintenant une année que nous partageons notre quotidien avec un petit hôte indésirable. Pas une semaine ne passe sans que nous ne nous trouvions face à un défi inédit, une nouvelle occasion de tester notre résistance physique et psychique, notre patience et nos compétences en matière de santé. Rappelons-nous le printemps 2020: tout à coup, le monde se retrouvait à l'arrêt. Le confinement était prononcé et les systèmes de santé se préparaient à faire face à une situation d'urgence, les scientifiques se démenaient pour trouver une parade au virus, et les politiques pour définir des mesures à même de protéger la population. Et vous, les médecins, vous êtes retrouvés catapultés au cœur de l'action. Le premier confinement a entraîné son lot de déséquilibres et d'incertitudes. Votre indéfectible engagement, et celui des infirmiers et infirmières, des assistantes médicales et des autres professionnels de la santé ont aidé la population générale et surtout les patients à traverser cette période difficile. En restant au chevet des patients sévèrement atteints et en accompagnant ceux se trouvant à l'article de la mort, par votre écoute et votre soutien attentif aux personnes fragilisées par l'incertitude et l'angoisse, vous avez apporté une contribution décisive.

\section{Chaque semaine, nous nous trouvons confrontés à de nouveaux défis qui nous mettent à l'épreuve.}

Les incertitudes quant au lendemain et à la façon dont le virus impactera nous ou nos proches représentent un immense défi pour les compétences en santé. Or, ces compétences sont notamment fonction d'un accès à des informations fiables, de la compréhension de ces informations et de la possibilité de les traduire en actes. Tout, donc, ne peut pas être ramené à la responsabilité (propre) de tout un chacun, un terme très utilisé ces derniers temps, avec des motivations très diverses.
Un sondage représentatif [1] de la fondation Careum révèle que la moitié ou presque de la population éprouve des difficultés à prendre des décisions adéquates face au Covid-19. Les changements fréquents dans les dispositions et les restrictions appliquées par les différents cantons accroissent son incertitude. Or, connaître les moyens de protection les plus efficaces constitue la base d'une stratégie efficace pour préserver sa santé et

Un immense merci à nos membres pour leur contribution décisive à la gestion de la pandémie.

celle de ses proches. En apportant éclaircissements et conseils sur des problématiques parfois complexes, nous aidons nos concitoyens à renforcer leurs compétences en santé, et contribuons à améliorer leur sécurité et leur sentiment de sécurité

Une société compétente en matière de santé parvient à cerner la portée d'une situation et connaît les mesures simples qui lui permettent de se protéger [2]. Comme vous pourrez le lire dans une des interviews de ce cahier (p. 160), la population suisse a la responsabilité comme les moyens de participer à la maîtrise de la pandémie. Par votre travail quotidien, vous contribuez, chers membres de la FMH, à améliorer les compétences en santé de notre population et à apaiser les incertitudes. Un immense merci pour votre engagement sans faille, votre travail, votre endurance face à l'adversité, en un mot pour votre contribution décisive à la mấtrise de la pandémie.

\section{Références}

1 Corona-bezogene Gesundheitskompetenz, consulté le 19 janvier 2021. www.migesplus.ch/publikationen/corona-bezogene-gesundheitskompetenz

2 Spring H. Health Literacy and COVID-19. Health Information \& Libraries Journal. 2020;37(3):171-2. https://doi.org/10.1111/hir.12322 